\title{
Letramentos das classes trabalhadoras e construção de identidade: um estudo de caso sobre os sentidos da escolarização
}

\author{
Karina Pacheco dos Santos* \\ PUC-PR \\ Nívea Rohling ${ }^{* *}$ \\ UTFPR \\ Recebido em: 30/06/2019 \\ Aceito em: 06/11/2019
}

\begin{abstract}
Resumo: Este trabalho descreve o histórico de letramento de Maria Lúcia. Objetivou-se analisar como práticas, eventos, e agências de letramento deslocaram/constituíram a identidade dessa mulher trabalhadora e de classe social desfavorecida economicamente. São mobilizados conceitos dos estudos do letramento e estabelecida uma relação com a noção de identidade. $\mathrm{O}$ estudo evidenciou que a identidade de Maria Lúcia está em constante constituição/descolamento, uma vez que precisa assumir ou negociar diferentes identidades para atuar nas práticas e nos eventos de letramentos.
\end{abstract}

Palavras-chave: Histórico de letramento. Letramento e identidades. Práticas e eventos de letramento. Agente e agência de letramento.

\begin{abstract}
This study describes the literacy historic of Maria Lúcia. The objective was to analyze how practices, events, agents and literacy agencies displaced/constituted the identity of this laborer and economically disadvantaged woman. For this purpose, concepts of literacy studies are mobilized and a relationship with the notion of identity are established. The study evidenced that the identity of Maria Lúcia is in constant constitution/detachment, since she need assume or negotiate different identities to act in the practices and events of literacies.
\end{abstract}

Keywords: Literacy historic. Literacy and identities. Practices and events of literacy. Agent and agency of literacy.

Resumen: Este trabajo describe la historia de letramiento de Maria Lúcia. Se objetivó analizar de qué forma las prácticas, los eventos y los sectores responsables pelos letramientos desplegaron o constituyeron la identidad de esta trabajadora de clase social desfavorecida económicamente. Se usan conceptos de los estudios de letramientos y se establece una relación con el concepto de identidad. El trabajo mostró que la identidad de Maria Lúcia se constituye y se despliega de forma constante, en la medida en que necesita asumir o negociar identidades distintas para interactuar en las prácticas y eventos de letramientos.

Palabras clave: Historia de letramiento. Letramientos y identidades. Prácticas y eventos de letramientos. Agente y agencia de letramiento. 


\section{Introdução}

Os estudos do letramento no Brasil, desde a década de 1980, investigam os usos da escrita em práticas sociais, valorizadas ou não, em diferentes contextos locais e globais (ROJO, 2009; KLEIMAN, 2008 [1995]). No início dos seus estudos, o letramento foi definido como "um conjunto de práticas sociais que usam a escrita, enquanto sistema simbólico e enquanto tecnologia, em contextos específicos, para objetivos específicos" (KLEIMAN, 2008 [1995], p. 19).

Ao se pensar para além das práticas escolares, em diferentes culturas ou canais e modos em que as práticas de letramento são efetivadas, alguns estudiosos da área do letramento (STREET, 2006; 2012; KLEIMAN, 2006; 2008 [1995]) passam a adotar o termo letramentos. Desse modo, ao assumir essa concepção, defende-se que nos diversos contextos culturais e sociais há múltiplos letramentos, o que significa atribuir valoração às diferentes práticas de letramento, as quais estão associadas a contextos sociais diversos (SILVA; ARAÚJO, 2010).

Nesse sentido, para sustentar que não há um letramento único, Street (2006) afirma que são múltiplas as formas de representação dos usos e dos significados de ler e escrever em épocas e contextos sociais distintos. Em oposição ao sistema que sustenta as práticas escolares, o modelo autônomo de letramento ${ }^{1}$, o autor propõe o modelo ideológico, admitindo que há múltiplos letramentos, em contextos culturais específicos e relacionados ao poder e à ideologia. Para Silva Filho e Rodrigues (2012, p. 523), adotar o modelo ideológico é uma forma de levar "em consideração as variáveis sociais ao se analisarem as causas e consequências dos usos da modalidade escrita por um indivíduo ou grupo de indivíduos”.

A escolarização, para os Novos Estudos do Letramento, é abordada como um dos tipos de práticas que envolvem os usos da escrita² ${ }^{2}$ Apesar de dominante, corresponde a

10 modelo autônomo de compreender o letramento correspondente a capacidades cognitivas individuais que podem ser medidas nos sujeitos, uma vez que considera que "há apenas uma maneira de o letramento ser desenvolvido, sendo que essa forma está associada quase que causalmente com o progresso, a civilização, a mobilidade social" (KLEIMAN, 2008 [1995], p. 21).

2Conforme esclarece Street (2014, p. 161), o modelo ideológico não nega o modelo autônomo e nem o considera neutro e imparcial, bem como reconhece a "importância dos aspectos técnicos da leitura e Revista Investigações, Recife, v. 32, n. 2, p. 122 - 149, Dezembro/2019 
algumas habilidades específicas, mas não a outras. A escola, segundo Kleiman (2008 [1995]), é a principal agência de letramento, mas, muitas vezes, toma como foco a aquisição de códigos, como o alfabético e o numérico, e em habilidades individuais. Desse modo, acaba por tangenciar as práticas sociais constitutivas dos usos da escrita e da leitura. No entanto, Silva e Araújo (2010, p. 320) afirmam que a escola não parece ser mais a principal agência de letramento, uma vez que "temos a possibilidade de ter acesso a diferentes tipos de letramento, há sujeitos não apenas letrados em uma dada agência, mas multiletrados".

Ainda, segundo Kleiman (2008 [1995]), com a reprodução de práticas ideológicas determinadas na escola para grupos étnicos e sociais, aliadas com o contexto de pobreza e analfabetismo, cria-se um ciclo de desigualdades no país.

Conforme explica Rojo (2009), em pesquisa mais recente, apesar da diminuição dos analfabetos no Brasil na década de 1980, durante os anos 1990, a relação entre escola e camadas populares é de insucesso e fracasso, uma vez que a escolarização não é vista como uma experiência significativa para as classes menos favorecidas.

Vale destacar que Kleiman se refere mais especificamente à Educação de Jovens e Adultos e está situando a problemática no final dos anos 80 e início dos anos 90. Diferentemente de Rojo (2009), que faz uma leitura mais atual. No entanto, é possível aventar que as discussões, no que tange aos letramentos escolares, são pertinentes contemporaneamente.

Confirmando essa situação, dados atuais do Instituto Nacional de Estudos e Pesquisas Educacionais Anísio Teixeira, em 2017, mostram que a evasão escolar ainda é um problema no país, dos alunos matriculados na $1^{\underline{a}}$ e na $2^{\underline{a}}$ série do ensino médio, em 2014 e 2015, respectivamente, 12,9\% e 12,7\% evadiram da escola (BRASIL; MEC, 2017). Os dados também são preocupantes no $9^{-}$ano do ensino fundamental, com uma taxa de $7,7 \%$ de evasão, e no $3^{\circ}$ ano do ensino médio, 6,8\%. Consequentemente, ao final do ensino fundamental, em média 3,2\% dos estudantes migram para a Educação de Jovens e Adultos (EJA). Nesse cenário, as taxas de reprovação também são significativas, por exemplo, $14,4 \%$ no $6^{\circ}$ ano do ensino fundamental; $15,3 \%$ no $1^{\circ}$ ano do ensino médio.

da escrita, tais como decodificação, correspondência som/forma e 'dificuldades' de leitura, mas sustenta que esses aspectos do letramento estão sempre encaixados em práticas sociais particulares". Revista Investigações, Recife, v. 32, n. 2, p. 122 - 149, Dezembro/2019 
Em relação ao ensino superior, nas últimas décadas, apesar de o governo federal criar políticas inclusivas de ações afirmativas, como o sistema de cotas nas universidades públicas para negros e estudantes de baixa renda; bem como em instituições particulares, como o Programa Universidade para Todos - Prouni, que já ofertou mais de 1,9 milhão de bolsas de 2005 a 2016 (BRASIL; MEC, 2018), e o Programa de Financiamento Estudantil (Fies), nem sempre a permanência nos cursos superiores é garantida (KRAINSKI, 2011). Segundo Costa e Dias (2015), o aumento no número de matrículas ocorre com a inclusão de classes menos favorecidas economicamente, os egressos de escolas públicas, mas que encontram dificuldades para apresentarem um bom desempenho e se manterem nos cursos de graduação. Para os autores, alguns fatores que dificultam a permanência no ensino superior estão relacionados ao fato de os estudantes precisarem conciliar trabalho e estudo, adaptarem-se a nova realidade acadêmica, que pressupõe mais autonomia e a participação em eventos e práticas de letramento dessa esfera, além de problemas financeiros vivenciados por muitos estudantes, dificultando, por exemplo, a aquisição de materiais, descolamento, alimentação e participação em atividades extraclasse ou eventos.

Essas adversidades, entre outros fatores, podem resultar na evasão. De acordo com os dados do Inep, em 2010, 11,4\% dos alunos matriculados abandonaram o curso superior; em 2014, esta taxa é ainda maior, 49\% (BRASIL; MEC, 2016). No entanto, para Costa e Dias (2015), a evasão precisa ser vista para além dos dados quantitativos, considerando alguns fatores desde a autoestima dos estudantes até políticas de democratização, permanência e inclusão no Ensino Superior. Conforme apontam os autores mencionados, sem mecanismos de inclusão e permanência, apenas garantir o acesso pode acentuar o quadro de desigualdades.

Nesse cenário sobre o acesso e a permanência no ensino superior, bem como da relação entre práticas de letramento e de escolarização, este artigo analisa o histórico de letramento 3 de uma licenciada em Ciências Sociais de uma universidade privada com

30 termo histórico de letramento é utilizado, nesta pesquisa, com base nos trabalhos de Silva Filho e Rodrigues (2012) e Silva e Araújo (2010). Os autores justificam que ainda não há uma definição clara da expressão na literatura, mas compreendem, fundamentadas em Kleiman (2006), que saberes escolares e não escolares precisam ser investigados pelos docentes, bem como a verificação da relação dessas práticas com questões de cidadania, identidade e inclusão. Ainda, ressaltam que "a convivência com práticas escolares e não escolares, advindas de diversas agências com as quais o sujeito mantém contato, se influenciam mutuamente e formam o seu histórico de letramento" (SILVA; 
vistas a observar como práticas, eventos e agências de letramento deslocaram/constituíram a identidade dessa mulher trabalhadora e de classe social desfavorecida economicamente. Nas análises, são explorados quatro enfoques do histórico de letramento da participante da pesquisa: eventos e práticas de leitura e escrita; os sentidos da escolarização; os letramentos acadêmicos; atuação social e na comunidade.

A escolha do estudo de caso de Maria Lúcia ${ }^{4}$ deu-se pelo fato de representar as classes trabalhadoras e desfavorecidas economicamente que tiveram acesso ao ensino superior na última década por meio de políticas públicas para educação, além de apresentar em seu histórico de letramento casos de insucesso e sucesso escolar. Desse modo, neste estudo de caso, partimos de questionamentos sobre os efeitos na constituição da identidade de Maria Lúcia ao participar de eventos e práticas de letramento das esferas escolar/acadêmica e de contextos não escolarizados. Além disso, indagamos quais são os sentidos atribuídos por ela à escolarização formal.

Para dar conta dessas questões de investigação, no pressuposto teórico da pesquisa, são delineados os conceitos produzidos no âmbito dos Novos Estudos do Letramento, tais como: eventos, práticas, agentes e agências de letramento (STREET, 2012; 2006; SILVA FILHO; RODRIGUES, 2012; KLEIMAN, 2006, SILVA; ARAÚJO, 2012). Além disso, para a análise da constituição/deslocamento da identidade da participante da pesquisa, é estabelecida uma relação entre as noções de identidade e letramentos (HALL, 2014; GEE, 2001; STREET, 2006).

\section{Práticas e eventos de letramento}

Em uma perspectiva que considera os sentidos das práticas e dos eventos de letramentos constituídos nos contextos sociais, Street (2012), com base em Heath, conceitua eventos de letramento como uma situação específica de usos da leitura e da

ARAÚJO, 2016, p. 316). Assim, definem o termo como as experiências relatadas pelos sujeitos de leitura e escrita em diversas situações comunicativas.

4Nome fictício adotado para preservar a identidade da participante.

Revista Investigaç̃̃es, Recife, v. 32, n. 2, p. 122 - 149, Dezembro/2019 
escrita que pode ser observada e descrita (por exemplo, verificar horários, folhear revistas, ler sinais de trânsito).

Já a expressão práticas de letramentos, de acordo com Street (2012), refere-se à busca de relacionar os eventos de letramento a sua natureza social e cultural. Para diferenciar os termos práticas e eventos, o autor explica que os eventos de letramento podem ser fotografados, as práticas não. Um exemplo de prática é o letramento escolarizado ou o letramento do cotidiano em dada cultura e contexto histórico. Segundo Silva e Araújo (2010, p. 319), "as práticas, assim como os eventos, são formadas por regras sociais que regulam o uso e a distribuição dos textos, prescrevendo quem pode produzir ou ter acesso a esses textos".

Silva Filho e Rodrigues (2012) retomam o exemplo clássico da literatura para explicar como um evento de letramento pode se configurar em uma prática de letramento. Por exemplo, o estudo de Shirley Brice Heath (1982), no evento de leitura de historinhas, em comunidades marcadas por níveis de escolarização e classes sociais diferentes, é possível observar estratégias distintas. Em comunidades mais desfavorecidas economicamente e com menor nível de escolarização, esse evento muitas vezes não ocorria. Ao contrário, em comunidades de maior nível de escolarização e nas classes média e alta, o evento ocorria, mas com estratégias diferentes, por exemplo, a interação esperada das crianças.

Nessa relação eventos/práticas de letramento, Street (2012) afirma que:

não se pode predizer antecipadamente o que dará significado a um evento de letramento e o que ligará um conjunto de eventos de letramento a práticas de letramento. As práticas de letramento referem-se a essa concepção cultural mais ampla de modos particulares de pensar sobre a leitura e de realizá-las em contextos culturais (STREET, 2012, p. 77).

Em uma pesquisa de natureza etnográfica, Street (2012) explica que é preciso dar sentido aos eventos de letramento a partir da conversa com as pessoas e da relação das experiências de escrita e leitura com as atividades que elas desenvolvem. Assim, nesta pesquisa, a partir da interação pesquisadora-pesquisada, buscamos relacionar o histórico de letramento de Maria Lúcia aos sentidos atribuídos por ela aos eventos e práticas de letramentos cotidianos e institucionalizados, como os letramentos típicos da escola e da universidade. 


\title{
Agente e agência de letramento
}

Ao considerar o letramento em uma perspectiva sócio-histórica, Silva Filho e Rodrigues (2012) explicam que é comum conceituar agentes de letramento como aqueles que medeiam os processos de aquisição da leitura e da escrita. Já Kleiman (2006), por sua vez, aborda o termo agente de letramento como uma forma de apresentar uma nova perspectiva à expressão enraizada de professor mediador, aquele que está no meio, por exemplo, estabelece uma mediação entre autor e leitor em um processo de leitura. A autora compreende que "um agente se engaja em ações autônomas de uma atividade determinada e é responsável por sua ação, em contraposição ao paciente, recipiente ou objeto, ou ao sujeito coagido" (KLEIMAN, 2006, p. 414). A autora também apresenta a noção de agência e agente social:

\begin{abstract}
a agência social é uma condição de poucos, aqueles que agem na coletividade, exercendo sua ação nos outros, em função dos objetivos de um grupo social. Um agente social trabalhando num determinado grupo tem capacidade para articular os interesses partilhados pelos membros da coletividade, organizar o grupo para a ação conjunta, gerar movimentos sociais e exercitar influência, como coletividade, no processo de tomar decisões. Assim, um agente teria a capacidade de decidir sobre um curso de ação, de interagir com outros agentes e seria capaz de modificar ou mudar seus planos segundo as ações, e mudanças resultantes dessas ações, do grupo e faria isso "estrategicamente", de uma forma que não seria entendida como a soma de interesses de membros individuais da coletividade. (KLEIMAN, 2006, p. 414-415).
\end{abstract}

Os conceitos de agente e agência são importantes para compreensão do papel que Maria Lúcia ocupa na comunidade em que vive, sendo, pois, uma agente social. No entanto, neste artigo, adotamos também a concepção mais ampla de Silva Filho e Rodrigues (2012, p. 525) para agente de letramento, que pode ser concebido como um indivíduo ou grupo "que medeie semioticamente a aprendizagem sobre algum uso social da modalidade escrita da língua, mesmo que essa ação mediadora não constitua prática consciente e sistemática visando produzir letramento.”. Ou seja, os autores adotam a concepção de que aqueles que influenciam na construção de práticas escritas de outros sujeitos são agentes de letramento, mesmo que não pertençam a instituições formais, como a escola e a universidade, mas também as práticas de letramento doméstico, por 
exemplo. Assumimos essa perspectiva com o intuito de identificar na narrativa de Maria Lúcia quais foram os agentes, não apenas das instituições escolares/acadêmicas, que participaram de seu histórico de letramento.

Para a expressão agências de letramento, Silva Filho e Rodrigues (2012, p. 526) concebem como "instituições ou grupos sociais em que se promovam eventos de letramento”. Apesar do papel central atribuído à instituição escolar como principal agência de letramento, Silva e Araújo (2010) consideram qualquer esfera de atividade humana, às quais os letramentos estão associados, como agências de letramento. Por exemplo, são agências de letramento as esferas da religião, comunidade, família, política, educação, profissão etc. Para os autores, essas áreas "ultrapassam a concepção de lugar/ambiente físico, referindo-se a um espaço sociodiscursivo, no qual há eventos de letramento regidos por práticas letradas construídas socialmente pelos sujeitos participantes das agências" (SILVA; ARAÚJO, 2010, p. 318). Neste trabalho, adotamos a concepção assumida pelos autores para agência de letramento, grupos distintos de atuação dos sujeitos em que são promovidos os eventos de letramento.

\section{Identidade e letramento}

$\mathrm{Na}$ perspectiva de Hall (2014), transformações na estrutura das sociedades modernas no século XX acarretaram em mudanças nas identidades pessoais, as quais não são mais concebidas como unificadas, produzindo um deslocamento ou descentração do sujeito (HALL, 2014). Para o autor, há uma fragmentação de paisagens culturais que envolvem questões de "classe, gênero, sexualidade, etnia, raça e nacionalidade" (HALL, 2014, p. 9). Dessa forma, a identidade do sujeito pós-moderno é construída e transformada de modo contínuo a partir das representações nos sistemas culturais e historicamente, ou seja, as identidades não são estabelecidas pelo biológico, mas nas historicidades, de modos diferentes e em diferentes momentos (HALL, 2014).

Esse processo de construção de identidades está relacionado ao contexto de transformação das sociedades na modernidade tardia, nas quais, devido à globalização e a outros fatores, há constantes transformações sociais. Segundo Hall (2014), as 
estruturas sociais são deslocadas na modernidade, ou seja, não há um único centro de poder, mas há vários centros. Assim, as sociedades na modernidade tardia são “caracterizadas pela diferença; elas são atravessadas por diferentes divisões e antagonismos sociais que produzem uma variedade de diferentes 'posições de sujeito' isto é, identidades" (HALL, 2014, p. 15).

Na relação identidade e letramento, de acordo com Street (2006, p. 466), "as práticas de letramento são constitutivas da identidade e da pessoalidade". Isto é, os modos de apropriação e de uso da leitura e da escrita estão relacionados às identidades e às expectativas sociais em relação a padrões de comportamento e papéis a exercer. $\mathrm{O}$ autor apresenta como exemplo as mulheres hispânicas nos Estados Unidos, as quais constroem uma identidade alternativa para livrarem-se da pobreza e da violência dos maridos. Ao frequentarem cursos em colleges, buscam se inserir em práticas e eventos de letramentos associados ao status social, no qual almejam conquistar e ocupar a identidade da mulher profissional, ao contrário dos letramentos domésticos ou cotidianos, de pouco prestígio e baixo status.

A partir do exemplo, é possível aventar que há um deslocamento da identidade dessas mulheres para atuarem em determinado contexto social; essa atuação está relacionada às práticas de letramento. Desse modo, Street (2006) explica que os diferentes letramentos estão relacionados às diferentes identidades e aos modos como elas são assumidas. Por exemplo, na instituição escolar, é possível assumir ou recusar as identidades relacionadas às práticas nesse contexto.

A noção de Identidade, para Gee (2001), pode ser pensada como uma "lente" analítica para investigações no campo educacional. Na perspectiva do autor, ao interagir em dado contexto discursivo, o ser humano é reconhecido por outros como "agindo e interagindo como um certo ‘tipo de pessoa”' (GEE, 2001, p. 99. Tradução livre5). Essa perspectiva considera a movência das identidades, tendo em vista que o tipo de pessoa é reconhecido como um ser, em um determinado tempo e lugar, pode mudar de momento a momento na interação, pode mudar de contexto para contexto, e, é claro, pode ser ambígua ou instável (GEE, 2001).

5 "Acting and interacting as a certain 'kind of person"'.

Revista Investigąções, Recife, v. 32, n. 2, p. 122 - 149, Dezembro/2019 
O pesquisador postula quatro modos como a identidade pode ser reconhecida, são elas: N-Identidade (Identidade natural), I-Identidade (Identidade Institucional), DIdentidade (Identidade discursiva), A-Identidade (Identidade por afinidades). Vale destacar que não se trata de categorizações estanques, isso porque, nas práticas interlocutivas, esses modos de reconhecer as identidades se imbricam.

A primeira categoria, $\mathrm{N}$-Identidade, diz respeito às características que o indivíduo traz ao nascer como, por exemplo, ser um gêmeo idêntico é um traço da N-Identidade. A força da N-Identidade é um fator sobre o qual o sujeito não tem controle, pois ela está ligada à natureza e não ao social. No entanto, Gee (2001, p. 102) explica que a NIdentidades precisa ser reconhecida pelo social: “[...] a N-Identidades ganha força como identidade através do trabalho das instituições, do discurso ${ }^{6}$ e do diálogo, ou dos grupos de afinidade, isto é, as mesmas forças que constituem nossas perspectivas sobre a identidade" (Tradução livre7).

A segunda categoria é a I-Identidade, relacionada às posições assumidas nas instituições. A sua fonte está ligada a um conjunto de autoridades, ou seja, a fonte do poder não é relacionada ao natural, mas às instituições. Esse poder perpassa um processo de autorização como, por exemplo, a posição de professor, que assume uma posição em dada instituição e é regido por leis, regras e princípios de funcionamento para atuar na posição assumida.

A terceira categoria é a D-Identidade, relacionada ao modo como o grupo social atribui determinados traços a uma pessoa. Ou seja, há um delineamento de um traço individual por meio de um reconhecimento, que não é relativo à natureza ou mantido por uma instituição. O autor explica a perspectiva discursiva com o exemplo de uma pessoa carismática, a fonte desse traço "é o discurso ou diálogo de outras pessoas" (GEE, 2001, p. 103, grifo do autor. Tradução livre ${ }^{8}$ ).

60 autor usa Discurso, com inicial maiúscula, para se referir ao discurso de modo mais amplo, ou seja, uma certa regularidade discursiva, como, por exemplo, discursos de afro-americanos, feministas médicos etc.). O que podemos aproximar ao conceito de formação discursiva em Análise do Discurso Francesa. E usa discurso, com inicial minúsculo, para fazer referência a enunciados de conversa ou de escrita, materializados nos textos.

7 "N-Identities must always gain their force as identities through the work of institutions, discourse and dialogue, or affinity groups, that is, the very forces that constitute our other perspectives on identity". 8 "The discourse or dialogue of other people".

Revista Investigações, Recife, v. 32, n. 2, p. 122 - 149, Dezembro/2019 
A quarta categoria apresentada por Gee (2001) é a identidade constituída por afinidade (A-Identidade), cuja "fonte desse poder não é a natureza ou uma instituição, ou até mesmo o discurso de outras pessoas e do diálogo sozinho, mas sim de um 'grupo de afinidade" (GEE, 2001, p. 105. Tradução livre99). Para grupos de afinidade, o autor apresenta do exemplo de fãs de Star Trek, que compartilham o acesso a práticas discursivas específicas, as quais permitem aos membros do grupo terem experiências necessárias. O poder, nesse caso, está ligado à partilha ou à participação. Além disso, para grupos de afinidade, a lealdade está relacionada, em primeiro lugar, às práticas em comum e, em segundo lugar, às pessoas "em termos de cultura ou traços compartilhados" (GEE, 2001, p. 105. Tradução livre ${ }^{10}$ ).

No processo de construção de um “tipo de identidade”, Gee (2001) afirma que há um sistema interpretativo de reconhecimento. Esse sistema interpretativo pode ser composto por: "pessoas com visões da natureza histórica e culturalmente diferentes; [...] as normas, tradições e regras de instituições; [...] o discurso e diálogo de outros; ou [...] o funcionamento de um grupo de afinidade" (GEE, 2001, p. 107-108. Tradução livre ${ }^{11}$ ).

Sobre essa categorização da identidade vale refletir que os traços identitários compõem um sistema interpretativo, e que não se trata de um processo passivo ao passo que os sujeitos podem, no interior das práticas discursivas de que participam, contestar, negociar ou refutar o modo como as identidades lhe são colocadas ou impostas. Isso porque, para Gee (2001), são as trajetórias e as narrativas individuais que constituem as identidades e "os Discursos são sociais e históricos, mas a trajetória e a narrativização das pessoas são individuais" (GEE, 2001, p. 112. Tradução livre ${ }^{12}$ ).

Nesse sentido, é partir da narrativa individual de Maria Lúcia, produzida no contexto desta investigação, que observamos o histórico de letramento para pensarmos a constituição/deslocamento de sua identidade. Partimos desse arcabouço teórico para compreender a construção/deslocamento e os conflitos de identidades de Maria Lúcia

9 "The source of this power is not nature or an institution, or even other people's discourse and dialogue alone, but an 'affinity group'".

10 "In terms of shared culture or traits".

11 "The interpretive system may be people's historically and culturally different views of nature; it may be the norms, traditions, and rules of institutions; it may be the discourse and dialogue of others; or it may be the workings of affinity groups".

12 "The Discourses are social and historical, but the person's trajectory and narrativization are individual". 
em sua narrativa pessoal, construída a partir das interações e situada em determinado tempo e no espaço social, que será detalhado na próxima subseção.

\section{Percurso Metodológico}

A presente investigação caracteriza-se como um estudo de caso, dentro de uma abordagem qualitativa de pesquisa. O estudo de caso é uma opção quando se pretende observar um sistema bem delimitado, ou seja, uma unidade com limites bem definidos, tal como uma pessoa, um programa, uma instituição ou um grupo social (ANDRÉ, 2009). Contudo, de acordo com a autora,

o interesse do pesquisador ao selecionar uma determinada unidade é compreendê-la como unidade. Isso, no entanto, não impede que ele esteja atento ao seu contexto e às suas inter-relações como um todo orgânico, e à sua dinâmica como um processo, uma unidade, uma ação. (ANDRÉ, 2009, p. 31).

Temos, pois, esses requisitos nessa pesquisa, uma vez que analisamos o histórico de letramento de uma licenciada em Ciências Sociais, com vistas a observar como práticas, eventos e agências de letramento constitutivos da identidade dessa mulher trabalhadora e de classe social desfavorecida economicamente.

Como instrumento de pesquisa para geração de dados, solicitamos que Maria Lúcia escrevesse um memorial em que relatasse aspectos como: histórico de letramento ao relatar práticas de leitura e escrita; inserção no letramento digital13; experiências profissionais antes do ingresso na universidade; motivações que a levaram ingressar no ensino superior; as adversidades pelas quais passou na escolarização e no ensino superior e como elas foram superadas; e outras questões que considerasse relevantes. Apesar do direcionamento estabelecido à participante, ela teria liberdade para escrever sobre outros temas que considerasse relevantes para a constituição da sua identidade.

Após a entrega do memorial, foi marcado um encontro presencial na casa de Maria Lúcia para entrevistá-la. Para o encontro, foram formulados alguns eficiente em práticas de leitura e escrita mediadas por equipamentos da tecnologia digital (XAVIER, 2011). 
questionamentos para uma entrevista semiestruturada, a qual foi gravada e alguns trechos são transcritos e analisados a partir dos pressupostos teóricos delineados neste estudo ${ }^{14}$. Na entrevista, a participante mostrou-se à vontade e respondeu aos questionamentos de modo satisfatório, acreditamos que isso ocorreu devido ao fato da proximidade que estabeleceu com uma das pesquisadoras deste estudo ${ }^{15}$, professora de Maria Lúcia na graduação no ano de 2014.

Para análise dos dados, optamos pela abordagem qualitativa e um enfoque interpretativo dos enunciados (SOUZA, 2011), de modo a investigar quais são os valores atribuídos por Maria Lúcia aos eventos e às práticas de letramento; e a participação dos agentes e agências de letramento no processo de constituição/deslocamento da identidade da participante da pesquisa. Após a escrita do estudo, ele foi enviado à Maria Lúcia para leitura, sugestões e acréscimos, no entanto, a participante não desejou fazer modificações ou inserções no texto.

\section{A trajetória de vida de Maria Lúcia}

Filha de trabalhadores rurais, Maria Lúcia nasceu em 1977 no interior do Paraná e é a nona filha de 10 irmãos. Os pais, nas palavras dela, tinham pouca leitura e nunca possuíram terra própria. No êxodo rural, vieram tentar a vida em Colombo, município situado na região metropolitana de Curitiba, onde trabalharam de chacareiros e cultivavam alimentos.

Ao iniciar os estudos com sete anos, passou por muitas adversidades, pois a escola era distante e precisava ir à pé. Por esses e outros motivos, teve duas reprovações escolares, nas $3^{\underline{a}}$ e $6^{\underline{a}}$ série, e uma desistência na $7^{\mathrm{a}}$ série em 1992.

\footnotetext{
14Após os trechos em que forem mencionadas as falas de Maria Lúcia, são inseridas as expressões "entrevista" e "memorial" para diferenciar os instrumentos que geraram determinado dado de pesquisa. 15 Neste momento, uma das pesquisadoras estabeleceu um vínculo profissional com Maria Lúcia, pois ela passava por uma fase de dificuldades e era frequentadora assídua das aulas de leitura e escrita acadêmica ofertadas na instituição onde ela estudava. Esse fator influenciou significativamente para a escolha da história de Maria Lúcia para a realização deste estudo, pois houve identificação com a luta dela para manter-se na graduação apesar das adversidades financeiras e familiares pelas quais passava. Maria Lúcia, quando convidada a participar da pesquisa, mostrou-se bastante interessada e acessível, atendendo a todos os pedidos durante a realização do trabalho.
}

Revista Investigaç̃̃es, Recife, v. 32, n. 2, p. 122 - 149, Dezembro/2019 
Após este período, desiludida com a escola e em busca de mudar sua situação, com 15 anos começa a trabalhar em uma casa de família, emprego que atribuía grande valor por lhe proporcionar benefícios que não tinha na casa dos pais, como telefone e chuveiro elétrico. Porém, após conhecer um namorado por um programa de rádio, namoro no rádio, engravidou e resolveu deixar a casa da patroa por vergonha, assim, foi morar com a irmã.

Quando a filha completa cinco anos, retoma os estudos na modalidade EJA e conclui o ensino médio em 2002. Em seguida, Maria Lúcia inicia um novo relacionamento e casa com o pai de sua segunda filha, trabalhador da construção civil. Nesse período, presta concurso para prefeitura de Colombo como agente comunitária e é aprovada. Após seis anos, devido às pressões do marido, pede exoneração e, em 2012, passa a trabalhar como auxiliar administrativa, na função de bibliotecária, por dois anos em uma escola estadual. Nesse momento, passa a ter um maior contato e fascínio pelos livros, influenciando em suas decisões posteriores.

Em 2013, com o incentivo da filha mais velha, decide prestar o Exame Nacional do Ensino Médio (Enem) e tentar uma vaga pelo Prouni para o curso de Ciências Sociais, para o qual conseguiu bolsa integral. Apesar das grandes dificuldades familiares e financeiras, conclui o curso em 2017. No momento, Maria Lúcia não atua como professora, mas deseja voltar a atuar na profissão e dar continuidade aos estudos.

As duas filhas da Maria Lúcia estudam, a mais velha cursa Administração, também por meio do auxílio de bolsas de estudo, graças ao incentivo da mãe ao custear cursos de informática e inseri-la no Programa Menor Aprendiz. A mais nova cursa o $2^{\underline{0}}$ ano do ensino médio e também pretende ingressar no ensino superior.

\section{Eventos e práticas de leitura e escrita de Maria Lúcia}

No ambiente familiar de Maria Lúcia, segundo ela, práticas de leitura e escrita eram raras. A mãe lia a bíblia, pois aprendeu a ler no Movimento Brasileiro de Alfabetização (MOBRAL) com um professor que apareceu na fazenda. Ao ser questionada se em casa os pais usavam a escrita e a leitura (por exemplo, contar 
histórias, fazer contas, listas de compras, entre outros), Maria Lúcia responde que sim, pois além das tarefas de chacareiros e agricultores na fazenda, a mãe frequentava grupos de oração e leitura bíblica; já o pai escrevia cartas aos irmãos que moravam em São Paulo, que eram lidas pelos filhos antes do envio. Todos esperavam com ansiedade as cartas voltarem com notícias dos familiares. Perguntada se ela e os irmãos eram motivados a ler e a escrever com o envio das cartas, responde que não, pois esses eram os únicos eventos de letramento que realizavam e não pensavam muito nessas coisas. Na casa dos pais de Maria Lúcia também não havia livros, apenas livros didáticos quando os filhos começaram a estudar, os quais eram comprados de segunda mão.

Assim, fora do ambiente escolar, o primeiro contato de Maria Lúcia com textos literários aconteceu quando trabalhou de empregada doméstica e escutava poesias no rádio. Somente em 2012, após concluir o ensino médio, quando atuou como bibliotecária, ela passa ter contato maior com a leitura de materiais impressos, mais especificamente livros.

\footnotetext{
Maria Lúcia: Já em 2012 fui trabalhar na Escola Estadual, como bibliotecária [...]. Com acesso ilimitado aos livros tive grande interesse por eles. Quando alguns dos alunos procuravam a biblioteca (isso não era praxe) ficava bem feliz e indicava alguns livros. Sempre lia o resumo pra saber o que andavam lendo. Se o resumo era interessante já pegava pra ler em casa. Acredito que esse contato com a leitura, e mesmo com os alunos foi de grande relevância para tudo que veio a acontecer posteriormente. (memorial).
}

Percebemos no relato que o contato com os livros a faz atribuir valor à leitura, ao mostrar entusiasmo em pegar exemplares na biblioteca. Além disso, reconhece que essa prática de letramento influenciou em seu futuro posteriormente. Antes desse maior contato com a leitura, em sua atuação como agente comunitária, Maria Lúcia escrevia relatórios e preenchia formulários em sua prática de entrega de remédios e trabalho com a comunidade.

Apesar da familiaridade com a leitura ter acontecido no ambiente escolar, Maria Lúcia não relaciona a prática da leitura com a escolarização. Desse modo, percebemos que as práticas de Maria Lúcia no ensino básico não motivaram práticas leitoras fora da escola, somente em uma situação posterior isso ocorre. Ao mencionar no relato que a procura por livros na biblioteca não era praxe, percebemos que a participante gostaria de ressaltar que, na escola, a leitura não é uma prática dos estudantes e nem sempre é 
valorizada. Com base em Rojo (2009), podemos inferir que Maria Lúcia não relaciona seus hábitos de leitura à escolarização devido à cobrança que há na escola pela leitura de cultura valorizada, nem sempre próxima da realidade de grande parte da população brasileira. Na época em que Maria Lúcia frequenta o EJA, em 2002, Rojo (2009) justifica que apenas $26 \%$ da população são capazes de ler textos de maior complexidade e que, apesar de não ser possível apresentar uma porcentagem sobre as obras presentes nos domicílios, elas eram, em sua maioria, de cunho didático ou religioso, e não da cultura letrada prestigiada, ou seja, os cânones literários.

Atualmente, Maria Lúcia é mais familiarizada com as práticas leitoras, em sua fala, observamos uma valoração dos teóricos das Ciências Sociais. Em sua casa, há livros didáticos e científicos em uma estante, os quais dividem espaço com obras de autoajuda e romances, leituras que Maria Lúcia gosta de fazer em seu tempo livre. Assim, inferimos que a instituição acadêmica teve grande influência para que ela passasse a ter contato com obras de status naquele meio, assumindo uma identidade institucional (GEE, 2001) de estudante universitária e futura professora.

\section{Os sentidos da escolarização}

Em seu período de escolarização, apesar do apoio dos pais, Maria Lúcia afirma que a distância do colégio e a falta de cultura escolar em casa influenciaram em duas reprovações, conforme relata no memorial:

Maria Lúcia: Quando iniciei na escola já com quase 7anos, foi bem complicado já que a família não tinha a cultura escolar. [...] No terceiro ano, em $1986,[\ldots]$ tive minha primeira reprovação escolar. No ginásio tive a segunda na 6a série. Era tudo difícil principalmente a matemática, fora isso o colégio era no centro da cidade e para chegar até lá, saia com minha irmã mais nova, sempre as 5:30 da manhã com frio, com chuva, andava por meia hora até pegar o ônibus escolar. Ele rodava por 1 hora e meia até chegar no colégio. Na hora de voltar fazia o mesmo trajeto chegávamos em casa por volta das 14:0o horas, com fome e cansadas por muitas vezes falávamos que não íamos mais pra escola. As Crianças da redondeza não continuavam com os estudos ou se os pais tinham condições financeiras pagavam passagens de ônibus em colégio mais próximos. O uniforme também tinha de ser comprado, era muito sacrifício. Leitura não se 
fazia, não tinha livros didáticos gratuitos e muitas vezes meu pai comprava os livros usados de algum que passava de ano. [grifos nossos]. (memorial).

Em seu relato, é evidenciado o sentido que, naquela época, a família atribuía à escolarização, apesar de, na entrevista, Maria Lúcia afirmar que os pais incentivam os estudos, pois era preciso aprender a ler e a escrever para arrumar um emprego. No entanto, as práticas de leitura da família não eram recorrentes e a condição financeira foi um entrave para que os filhos pudessem estudar, tanto na aquisição de uniforme e materiais didáticos quanto de transporte. Maria Lúcia também denuncia as condições de outras pessoas de sua comunidade ao afirmar que as crianças da redondeza não podiam dar continuidade aos estudos, o que evidencia a sua consciência e preocupação social.

O aparente fracasso escolar de Maria Lúcia na escolarização, devido às desistências e às reprovações, confirma os dados apresentados por Rojo (2009) ao afirmar que, na década de 1990, a relação da escola com as populações carentes é de fracasso e insucesso. A autora conclui que, nessa época, o acesso ao ensino fundamental foi garantido, mas não a permanência e o sucesso escolar das classes menos favorecidas.

$\mathrm{Na}$ entrevista com Maria Lúcia, também é perceptível que pouco é tematizada e valorada a escolarização nos anos iniciais. Para ela, não faziam sentido os letramentos escolares, pois o que buscava mesmo eram condições para ser inserida no mercado de trabalho. Podemos aventar que isso ocorra em virtude da prevalência no letramento escolar do modelo autônomo (STREET, 2006; 2014) de letramento com enfoque na aquisição do código escrito.

$\mathrm{Na}$ entrevista ${ }^{16}$, emerge uma valoração negativa em relação à escola como se evidencia em sua fala adjetivar a escola como "chata", além do prolongamento no advérbio "muito", e ao afirmar que os professores não tinham paciência.

Maria Lúcia: (...) sem conta que a escola era mui:::to::: chata... não sei se era né? a escola... as professoras não tinha paciência que nem eles ((professores universitários)) explicam que a gente tem que ter... tem que ter mudado a forma de forma professor né (...) e pense::: nem existia pedagogia... os professores... eram assim sei lá... magisté:::rio... só segundo grau já conseguia ser professor naquela época. (entrevista).

16Para a transcrição das falas de Maria Lúcia, foram utilizadas as normas para transcrição de entrevistas gravadas disponíveis em: <http://www.psrossi.com/Normas_entrev.pdf>. Acesso em: 10 jan. 2018. 
No entanto, é perceptível o valor que concede à formação do professor atualmente, pois afirma que o modo de formar professores mudou e aumentaram as exigências para atuação no magistério. Além disso, Maria Lúcia considera importante dar continuidade aos estudos para ser uma boa profissional, relacionando, desse modo, formação docente e atuação profissional. Inferimos que essa valoração tenha relação com a atual formação de Maria Lúcia, o fato ter cursado uma licenciatura a faz assumir a I-Identidade (GEE, 2001) de professora e a considerar a formação desses profissionais. Também podemos perceber essa nova postura de Maria Lúcia quando afirma não sei se era né?, apesar de dizer que a escola era chata, ela mesma questiona essa afirmação em seguida, apresentando um conflito em relação à valoração que atribui à instituição escolar.

Ainda sobre seu processo de escolarização, o preconceito que afirma ter sofrido na escola está relacionado ao fato de ter vindo do interior e apresentar em sua fala marcas regionais. Além disso, pelo fato de ter tido duas reprovações, sentia-se estigmatizada.

Maria Lúcia: (...) você vai chega lá ((na escola)) você vai ter que muda seu jeito de fala... a gente sofria muito lá... falava OCÊ... a gente falava ocê né (...) "OCÊ PEGA ISSO”... "OCÊ NÃO FAZ ISSO"... ((na escola)) não podia fala ocê... você tinha que fala "É VOCÊ" ((risos)). (entrevista).

No trecho, percebemos que Maria Lúcia dá entonação à palavra que era comumente usada pelos alunos e corrigida pela professora, atribuiu o discurso direto a última expressão, “é você”, para reproduzir o discurso de correção da professora. Esse dado enfatiza que a forma como a escola trata as variedades linguísticas está relacionada ao modelo autônomo de letramento (STREET, 2006; 2014).

Maria Lúcia também relatou que havia um preconceito enraizado nas famílias vindas do interior sobre a escolarização das mulheres e que ela se considerava privilegiada. Conta que os pais não eram alfabetizados formalmente, que o avô chegou a pagar um professor para o pai, mas não para as tias, pois consideravam que as mulheres não precisavam estudar para exercer as tarefas domésticas. Relatou que os próprios donos das fazendas pagavam para alguns filhos dos empregados estudarem, mas nunca para as mulheres. 
Nessa parte do relato, observamos uma questão emblemática de identidade social (gênero social) e letramento, que remete à história de nosso país, uma vez que as mulheres foram, por um longo período, privadas do acesso aos letramentos escolares por serem mulheres. Nesse caso, a partir de uma N-Identidades (GEE, 2001), constrói-se socialmente uma identidade discursiva, pois, pelo fato de serem mulheres, consideravam que elas não precisavam de escolarização para casar e, consequentemente, cuidar da casa e dos filhos, funções historicamente atribuídas às mulheres. Assim, as mulheres acabavam assumindo a posição de cuidar das tarefas do lar, aprendendo letramentos domésticos/cotidianos, como fazer compras, fazer contas básicas, escrever cartas ou bilhetes, entre outros (STREET, 2006). Desse modo, não havia sentido estudar, a não ser que quisessem contestar essa posição e trabalharem fora, como ocorre com Maria Lúcia. Mas, mesmo buscando uma escolarização inicial, ao não dar continuidade, por não atribuir sentido à escolarização, ela só consegue colocação no mercado de trabalho como empregada doméstica.

No entanto, não podemos afirmar que o emprego inicial de Maria Lúcia tem relação direta com a pouca escolarização, uma vez que nem sempre a escola prepara os sujeitos para o mercado de trabalho e o letramento escolar não está associado necessariamente à ascensão e à mobilidade social (STREET, 2006), como é evidenciado posteriormente no histórico de letramento de Maria Lúcia após a conclusão do ensino superior. Assim, a relação entre letramento escolar/acadêmico e a ascensão social, bem como a emancipação feminina, são mitos do letramento, conforme aponta Kleiman (2008 [1995], p. 34): "uma ideologia que vem se produzindo nos últimos trezentos anos, e que confere ao letramento uma enorme gama de efeitos positivos, desejáveis, não só no âmbito da cognição, mas também no âmbito social”.

Por fim, ao voltar a estudar e concluir o ensino fundamental e médio, novamente Maria Lúcia relata que estava pensando na questão financeira e em ter um certificado de conclusão do ensino básico. No entanto, atualmente, ela considera que isso fez diferença na sua vida, pois teve acesso a novas oportunidades, como conseguir passar em um concurso e não precisar mais trabalhar como empregada doméstica ou em restaurantes. Na sequência, discorremos sobre a inserção de Maria Lúcia nas práticas de letramento acadêmico. 


\section{Os letramentos acadêmicos}

Como mencionado anteriormente, motivada pela filha mais velha que, na época, trabalhava na biblioteca de uma universidade, Maria Lúcia decidiu prestar o Enem e conseguiu uma vaga com bolsa integral para o curso de Ciências Sociais. Ao ingressar no ensino superior, novamente passou por dificuldades financeiras, pensou em desistir do curso, pois, apesar da bolsa de estudos integral, precisava pagar o transporte e outros gastos na universidade, dependendo da ajuda do companheiro.

Essa situação pela qual Maria Lúcia passou demonstra que garantir o acesso ao ensino superior pelas classes menos favorecidas não assegura também a permanência (COSTA; DIAS, 2015; KRAINSKI, 2011). Um modo que encontrou para manter-se no curso foi trabalhando novamente como empregada doméstica e participando do Programa Institucional de Bolsas de Iniciação Científica (PIBID), conforme relata:

Maria Lúcia: (...) muitos sobrevivia por causa do PIBID... continuaram na universidade por causa do PIBID né?... porque tinha os quatrocentos reais para paga passagem lá... é::: parcelavam (a conta)... parcelavam o notebook... teve casos assim né... (entrevista).

O Programa PIBID, além de auxiliá-la na questão financeira, possibilitou-lhe também acesso a práticas do ambiente escolar e da construção I-Identidade (GEE, 2001) como professora, pois além de atuar em sala de aula, elaborava projetos e preparava atividades e planos de aula. Maria Lúcia afirmou que a participação como bolsista ajudou muito a compreender as regras e funcionamento do cotidiano escolar como professora. Apesar de já ter atuado como bibliotecária, nesse momento, assume um papel diferente na instituição escolar.

Em sua atuação no ensino superior, também encontrou grandes dificuldades na leitura e escrita de textos acadêmicos, disse que foi aprender o que eram os gêneros resumo e resenha na universidade. Nesse sentido, Fischer (2008) afirma que as dificuldades dos estudantes de atuarem nos eventos de letramento acadêmico estão relacionadas com a formação letrada desses sujeitos na escolarização e com fatores 
sociais, questões que não podem ser desconsideradas pelas instituições de ensino superior.

Além disso, percebemos que, apesar de uma nota satisfatória na redação do Enem, Maria Lúcia não se sente preparada para atuar nas práticas de letramento acadêmico, o que ratifica a afirmação de Kleiman (2008 [1995]), que a escola, muitas vezes, prepara os estudantes apenas para interpretação e produção de textos expositivos e argumentativos, o clássico modelo escolar.

Devido às dificuldades descritas, Maria Lúcia procurou um programa de promoção letramento acadêmico na universidade para poder acompanhar as disciplinas da graduação e aprender a produção de textos acadêmicos. Nesse aspecto, Maria Lúcia apresenta em seu memorial algumas nas dificuldades pelas quais passou durante a graduação:

Maria Lúcia: Entrei na sala e a aula era de Ciência Política, a professora falava bonito, com sua linguagem acadêmica já achei que não era pra mim. Nisso já tinha distribuído a ementa, com as leituras a serem feitas durante o semestre. Conversando com os alunos descobri que tinha que fazer tal de "Fichamento" pra cada aula, e valendo pontos pra média. Até a gente entender o que era fichamento levou muito tempo. [grifos nossos]. (memorial).

A partir desse relato, percebemos o choque que Maria Lúcia passa ao deparar-se com os eventos e práticas da instituição acadêmica, desde a fala da professora até produção de textos acadêmicos, ambos distantes de sua realidade (FISCHER, 2008). Em sua fala, ela também inclui os colegas e assume que outros passavam pelas mesmas dificuldades ao usar o pronome de primeira pessoa do plural: até a gente entender.

Nesse momento, há uma construção em conflito da I-Identidade de estudante universitária, que precisa adaptar-se às práticas e às normas da instituição. Maria Lúcia também relatou que encontrou grandes dificuldades na elaboração do Trabalho de Conclusão de Curso (TCC), por exigir uma escrita acadêmica e práticas de pesquisa com as quais não tinha familiaridade. No TCC, com base na sua experiência no PIBID, abordou o ser professor na visão de ex-bolsistas do programa, o que demonstra o quanto foi significativa essa experiência para Maria Lúcia na constituição da sua identidade como professora.

Questionada sobre o uso do computador para atuação nos eventos de letramento na universidade, Maria Lúcia relata que a filha mais velha realizava todas as tarefas que 
ela precisava, como envio de trabalhos, digitação dos textos, acesso ao sistema de notas, entre outros. Com o tempo e ajuda da filha, consegue aprender a realizar todas essas atividades e hoje está mais familiarizada com as práticas do letramento digital. Desse modo, com base na concepção de Silva Filho e Rodrigues (2012), inferimos que a filha atua como uma agente de letramento na vida de Maria Lúcia, tanto no acesso quanto na permanência no ensino superior.

Neste momento da vida, há grande valorização por parte de Maria Lúcia ao relatar sua experiência no ensino superior, devido ao status que é atribuído socialmente àqueles que conseguem um diploma de graduação. Ao trabalhar como empregada doméstica relata que tinha muito orgulho de contar às patroas que cursava Ciências Sociais; estas, por sua vez, ficavam orgulhosas ou espantadas. Nesse momento, percebe-se que há a construção de uma D-Identidade (GEE, 2001) que é buscada por Maria Lúcia, a partir do reconhecimento da sociedade e da família.

Ao falar do marido, observa-se que Maria Lúcia não recebeu o apoio necessário e esperado para os estudos, o que demostra a constituição da D-Identidade em conflito, uma vez que o esposo desejava que ela cuidasse das tarefas de casa, como preparar o jantar etc. Maria Lúcia, por sua vez, gostaria de ser reconhecida como mulher, companheira, mas também como estudante que buscava melhor formação e condições para a família, conforme relata no memorial:

\footnotetext{
Maria Lúcia: Ele também era assalariado e começou a restringir a ajuda pois pra ele não fazia sentido sair toda noite pra estudar, deixar de fazer a janta e não suportou mais tal situação [...]. Pediu o divórcio foi pra longe. Fiquei mal por um tempo, mas agora vejo que foi o melhor pra mim. Trabalhava como diarista, limpando casas para garantir o sustento e as passagens de ônibus. Seria ingratidão de minha parte receber uma bolsa integral e não dar continuidade por falta de dinheiro. [grifos nossos]. (memorial).
}

Durante e após concluir o ensino superior, Maria Lúcia passa a atuar em eventos relacionados ao letramento acadêmico, como fazer pesquisa e participar de congressos. Ela relata que tudo é novidade, como quando participou de um congresso em Brasília, pois precisou escrever o trabalho, comprar passagem de avião, buscar hospedagem, entre outros, além de assumir uma posição de pesquisadora no congresso. Novamente, a partir de novos eventos e práticas de letramento em que é inserida, há a construção de uma nova identidade histórica de letramento de Maria Lúcia. Isso está em consonância 
com a afirmação de Street (2006), que há uma relação direta entre as práticas de letramento e a construção de identidades.

\section{Letramentos sociais e atuação na comunidade}

Maria Lúcia fazia parte do conselho de saúde de sua comunidade, porém pediu para sair em 2017 para dedicar-se às atividades da universidade. No entanto, ela ainda participa das reuniões da comunidade e pretende voltar a atuar. Nas reuniões, ela ajuda voluntariamente na entrega medicamentos e conversa com os pacientes. Questionada se neste trabalho há contato com a leitura e a escrita, Maria Lúcia afirma que não, que o contato é oral com as pessoas e que fichas e relatórios são preenchidos pelos agentes comunitários, função que já exerceu no passado. Desse modo, inferimos que nessa prática os eventos de letramento que envolvem diretamente a escrita são mais raros.

Em sua fala, fica evidente a valorização que Maria Lúcia atribui atualmente aos estudos para mudar a realidade de sua comunidade. Conta que resolveu cursar Ciências Sociais porque, quando atuou como agente comunitária, achava que a sociologia seria um modo de realizar pesquisas em seu bairro e trazer mais informações às pessoas. Afirmou que se inspirava em sociólogos como Betinho ao ver a pobreza de seu povo. Em alguns trechos da entrevista, deixa clara a importância do engajamento social e a necessidade de atuar como uma agente social:

\footnotetext{
Maria Lúcia: a luta é todo dia né (...) e vão complicA né... porque na verdade eles ((o governo)) não querem que os pobre estuda... é verdade isso (...) pobre é só pra trabalha... uma coisa que eu penso é trabalha aqui no bairro com essa comunidade (...) a gente conhece aqui né (...) aqui a gente já tá mais de trinta ano::: a gente pensa qual seria a parcela da população que poderia... poderia ajuda né

Pesquisadora: trabalhar na comunidade?

Maria Lúcia: na comunidade... talvez a escola seria um lugar ideal né... um lugar fazer um projeto para fora da escola... na escola a gente é muito limitado também né... tem que só dar aula... dar o conteúdo e pronto... não dá tempo de você faze outras coisas. (entrevista).
}

Quando atuou em duas escolas como professora substituta pelo Processo Seletivo Simplificado (PSS), durante quatro meses, afirmou que não teve muito tempo para 
desenvolver projetos sociais, que eram a sua vontade, pois relatou que, quando assume uma turma no final de ano, o professor precisa dar conta do programa proposto e realizar tarefas burocráticas.

Nesse relato, percebemos que Maria Lúcia tem contanto com os eventos de letramento relacionados à atuação como professora, como preparar aulas e preencher livros de chamada, assumindo assim, uma identidade institucional. Nessa atuação, Maria Lúcia apresenta consciência da importância de desenvolver um projeto social que faça sentido aos seus alunos, porém entra em conflito com as regras e tarefas de uma instituição escolar. Consequentemente, percebemos um conflito de sua D-Identidade com a sua I-Identidade (GEE, 2001). Maria Lúcia afirma que gostaria de ser concursada para ter mais estabilidade e poder desenvolver projetos sociais. Seu desejo é também atuar como líder na comunidade, sendo reconhecida e ajudando os moradores locais.

Questionada sobre a ascensão social das comunidades mais carentes e sobre as oportunidades, Maria Lúcia afirma que há falta de informações para as pessoas que, muitas vezes, não ficam sabendo dos programas sociais. Consequentemente, ela afirma que é preciso haver agentes sociais que levem informações às pessoas da comunidade. Ela também afirma que lá não há cultura escolar, pois as pessoas priorizam o trabalho e não atribuem valor à escolarização e ao ensino superior:

Maria Lúcia: (...) isso é longe da realidade... isso não é:.... é... porque por causa exatamente por causa.... da cultura que eles têm né... "UNIVERSIDADE PARA QUÊ NÈ? Se eu tenho que TRABALHA::? Se eu tenho que SOBREVIVE::? Se eu tenho que ter um SALÁRIO::?" Esse sonho de universidade nas comunidades é muito pequeno... não é... são muito pouco. (entrevista).

Percebemos que em sua fala ela utiliza o discurso direto para reproduzir uma fala comum em sua comunidade e está associada à desvalorização à escolarização. Também há ênfase em sua voz para evidenciar essa situação.

Questionada se participa de movimentos sociais, ela disse que não tem uma bandeira em si, nem um partido, mas se considera de esquerda e que sempre participa das manifestações populares, como em protestos e greves. Nessas situações, ela relata que são mobilizados alguns eventos de letramento, como conferir nas redes sociais quais serão as próximas manifestações, preparar cartazes, postar textos e compartilhar informações nas redes sociais, entre outros. Há também as aulas públicas, nas quais integrantes dos sindicatos palestram aos ouvintes. Percebemos que ao participar dessas 
manifestações, há identidades institucionais (filiações partidárias e sindicais) e grupos de afinidade (GEE, 2001) em construção (colegas que compartilham das mesmas ideologias e práticas) articulados com práticas e eventos de letramento.

No momento, apesar de atuar como voluntária em seu bairro, Maria Lúcia não conseguiu emprego como professora para realizar os projetos que deseja. Ela atua como garçonete em um baile na região do seu bairro, mas que deseja voltar a atuar como professora e dar continuidade aos estudos em uma pós-graduação.

\section{Considerações finais}

Ao final da entrevista, Maria Lúcia afirmou que, após concluir o ensino superior, novas oportunidades surgiram em seu histórico de letramento e realizou práticas que nunca imaginou fazer antes, como viajar e conhecer outras pessoas e lugares. Assim, o acesso à instituição acadêmica permitiu que ela participasse de novas práticas e eventos de letramento, bem como foi muito importante para a constituição de sua identidade como professora.

No entanto, o histórico de letramento de Maria Lúcia também evidencia que o letramento não está necessariamente relacionado com a promoção social, no que diz respeito à ascensão a uma classe social economicamente mais favorecida. Apesar de Maria Lúcia ter conseguido acesso a um letramento de prestígio, ainda não consegue atuar na profissão desejada e nem melhorar sua situação financeira, devido a fatores que não tem relação com a sua formação, precisando atuar em uma área diferente para manter o sustento da família.

Ao perceber que houve grande mudança no deslocamento da sua identidade como mulher, Maria Lúcia relata que se sente mais independente e compreende as questões feministas, como não ser submissa a um companheiro e realizar apenas tarefas domésticas. Além disso, afirma que agora entende que é uma pessoa inacabada e em constante transformação. Para Maria Lúcia, o acabamento que as pessoas lhe dão é importante, mas reconhece que é difícil atender as expectativas e estar em constante 
transformação. Fato que mostra uma D-Identidade em construção e conflito (GEE, 2001).

Maria Lúcia também afirma que hoje atribui mais valor a escolarização, mas que a educação não é somente números para apresentar a sociedade e aos programas de desenvolvimento, assim, precisa ser mais inclusiva. Acredita que é uma agente de mudança e que pode conscientizar os estudantes que a educação não precisa de reformas, mas de revolução. Percebemos, desse modo, que a escolarização só passa a fazer sentido para Maria Lúcia no ensino superior, quando escolhe um curso que tenha relação com a sua atuação social e com a realidade da comunidade em que vive. Pois, conforme afirma Rojo (2009), os letramentos não fazem sentido quando apenas enfocam em habilidades individuais, mas quando estabelecem relações com as culturas locais e estão ligados às práticas de leitura e escrita no contexto social dos indivíduos.

A partir dos dados gerados e analisados, compreendemos que a identidade de Maria Lúcia está em constante construção/deslocamento, pois ela assume diferentes identidades em seu histórico de letramento, como mãe, mulher, trabalhadora, estudante universitária e professora. Essas identidades são construídas em tempos e espaços situados e estão relacionadas aos eventos e às práticas de letramentos. Pois, conforme afirma Street (2006, p. 471), "os letramentos podem ser lugares de negociação e de transformação”, uma vez que os indivíduos negociam e assumem, ou não, papéis que lhe são atribuídos.

\section{Referências}

ANDRÉ, M. E. D. A. Etnografia da prática escolar. 16. ed. São Paulo: Papirus, 2009. BRASIL; MINISTÉRIO DA EDUCAÇÃO. Censo da Educação Superior de 2014 (Resumo Técnico). Brasília: Inep, 2016. Disponível em: <http://download.inep.gov.br/download/superior/censo/2014/resumo_tecnico_censo_ educacao_superior_2014.pdf>. Acesso em: 15 jan. 2018.

Inep divulga dados inéditos sobre fluxo escolar na educação básica. Portal Inep,

2017. Disponível em: <http://portal.inep.gov.br/artigo//asset_publisher/B4AQV9zFY7Bv/content/inep-divulga-dados-ineditos-sobre-fluxoescolar-na-educacao-basica/21206>. Acesso em: 15 jan. 2018. 
Prouni - Programa Universidade para todos. Portal Prouni. Disponível em: <http://prouniportal.mec.gov.br/o-programa>. Acesso em: 15 jan. 2018.

COSTA, S. L. da; DIAS, S. M. B. A permanência no ensino superior e as estratégias institucionais de enfrentamento da evasão. Jornal de Políticas Educacionais, v.9, n.17-18, p. 51-6o, jan./jun., ago./dez. 2015. Disponível em: <http://revistas.ufpr.br/jpe/article/view/38650>. Acesso em: 15 jan. 2018.

FISCHER, A. Letramento acadêmico: uma perspectiva portuguesa. Revista Acta Scientiarum: Language and Culture, Maringá, v. 30, n. 2, p. 177-187, 2008. Disponível em: <http://periodicos.uem.br/ojs/index.php/ActaSciLangCult/article/view/2334/2334>. Acesso em: 13 ago. 2015 .

GEE, J. P. Identity as an Analytic Lens for Research in Education. Review of Research in Education, v. 25, pp. 99-125, 2001.

HALL, S. A identidade cultural na pós-modernidade. Tradução de Tomaz Tadeu da Silva e Guacira Lopes Louro. Rio de Janeiro: Lamparina, 2014.

HEATH, S. B. What no bedtime story means: narrative skills at home and school. Language and Society, v. 11, p. 49-76, 1982. Disponível em: https://people.ucsc.edu/ gwells/Files/Courses_Folder/documents/Heath.BedtimeStori es.pdf. Acesso em: 03 nov. 2019.

KLEIMAN, A. B. Modelos de letramento e as práticas de alfabetização na escola. In: KLEIMAN, A. B. (Org.). Os significados do letramento: uma nova perspectiva sobre a prática social da escrita. Campinas: Mercado das Letras, 2008 [1995], p. 15-61.

. Professores e agentes de letramento: identidade e posicionamento social. Filologia e Linguística Portuguesa, n. 8, p. 409-424, 2006. Disponível em: <http://www.revistas.usp.br/flp/article/view/59763/62872>. Acesso em: 10 jan. 2018.

KRAINSKI, L. B. Permanência e Sucesso no Ensino Superior: uma questão de direito. In: CONGRESSO NACIONAL DE EDUCAÇÃO - EDUCERE, 5; SEMINÁRIO INTERNACIONAL DE REPRESENTAÇÕES SOCIAIS, SUBJETIVIDADES E EDUCAÇÃO - SIRSSE, 1., Curitiba, 2011. Anais... Curitiba: Pontifícia Universidade Católica do Paraná, 2011. Disponível em: <http://educere.bruc.com.br/CD2011/pdf/5678_2987.pdf>. Acesso em: 15 jan. 2018.

ROJO, R. Letramentos múltiplos, escola e inclusão social. São Paulo: Parábola Editoral, 2009 . 
SILVA FILHO, V.; RODRIGUES, R. H. Letramento e construção de identidade na terceira idade: um estudo de caso. Linguagem em (Dis)curso, SC, v. 12, n. 2, p. 517-544, maio/ago. 2012. Disponível

em: <http://www.portaldeperiodicos.unisul.br/index.php/Linguagem_Discurso/article/vie w/1098>. Acesso em: 10 jan. 2018.

SILVA, E. M. da; ARAÚJO, D. L. de. Correlação entre carta-protesto e histórico de letramento do candidato: uma análise de redações do vestibular. Linguagem em (Dis)curso, Palhoça, SC, v. 10, n. 2, p. 315-338, maio/ago. 2010. Disponível em: <http://www.scielo.br/pdf/ld/vion2/vion2ao5.pdf>. Acesso em: 10 jan. 2018.

SOUZA, A. L. S. Letramentos de reexistência: poesia, grafite, música, dança: hip-hop. São Paulo: Parábola Editorial, 2011.

STREET, B. Letramentos sociais: abordagens críticas do letramento no desenvolvimento, na etnografia e na educação. Tradução de Marcos Bagno. São Paulo: Parábola Editorial, 2014 .

. Eventos de letramentos e práticas de letramento: teoria e práticas nos novos estudos do letramento. MAGALHÃES, I. (org.). Discursos e práticas de letramento: pesquisa etnográfica e formação de professores. Campinas, SP: Mercado das Letras, 2012, p. 69-92. (Coleção Letramento, Educação e Sociedade).

- Perspectivas interculturais sobre o letramento. Filologia e Linguística Portuguesa, São Paulo, n. o8, p. 465-488, 2006. Disponível em: <http://www.revistas.usp.br/flp/article/view/59767/62876>. Acesso em: 14 jan. 2018.

XAVIER, A. C.. Letramento digital: impactos das tecnologias na aprendizagem da Geração Y. Calidoscópio, v. 9, n. 1, p. 3-14, jan./abr. 2011. Disponível em: <http://revistas.unisinos.br/index.php/calidoscopio/article/view/748/149>. Acesso em: 03 nov. 2019.

\footnotetext{
${ }^{*}$ Mestre em Estudos de Linguagens pela Universidade Tecnológica Federal do Paraná; Docente do curso de Letras Português-Inglês da Pontifícia Universidade Católica do Paraná/Campus Curitiba.

${ }^{* *}$ Mestre e Doutora em Linguística pela Universidade Federal de Santa Catarina; Docente do Programa de Pós-Graduação em Estudos de Linguagens (PPGEL), da Universidade Tecnológica Federal do Paraná/Campus Curitiba.
} 